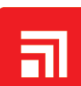 Journal of Nuclear Physics, Material Sciences, Radiation and Applications

\section{Performance of PIXE Technique through a Geochemical Analysis of High Grade Rocks}

\author{
A. V. S. Satyanarayana ${ }^{1 *}$, M. Jagannadharao ${ }^{2}$, K. Chandra Mouli ${ }^{3}$ and B. Seetarami Reddy ${ }^{4}$ \\ ${ }^{1 *}$ Department of Engineering Physics, Andhra University, Andhra Pradesh, India \\ ${ }^{2}$ Department of Geology, Andhra University, Visakhapatnam-530003, Andhra Pradesh, India \\ ${ }^{3}$ Department of Engineering Physics, Andhra University, Visakhapatnam-530003, Andhra Pradesh, India \\ ${ }^{4}$ Department of Nuclear Physics, Andhra University, Visakhapatnam-530003, Andhra Pradesh, India
}

"Email: savs.viit@gmail.com

\section{ARTICLE INFORMATION}

Received: October 7, 2019

Revised: January 13,2020

Accepted: January 18, 2020

Published online: January 20, 2020

Keywords:

High grade metamorphic rock, Charnockites, Complexity of matrix, Geochemical analysis,

PIXE performance evaluation, AAS technique

DOI: $10.15415 /$ jnp.2019.71002

\section{ABSTRACT}

It has been an argument that some of the elements present in geological material by using PIXE analysis are purely determined or could not be determined at all, due to various reasons including the matrix. It is felt that a systematic investigation needs to be designed and implemented to understand the limitation of PIXE in certain elements. The high-grade rocks selected, are analyzed both by PIXE as well as AAS and the results are authenticated by using a USGS reference material, Basalt, studies of literature. It is believed that the accuracy of problematic elements, especially from high grade rock can be improved and the conditions of PIXE can be standardized for various elements under different combinations. The reasons behind the poor performance of Proton Induced X-ray Emission in case of certain elements have been established.

\section{Introduction}

The nuclear science has been in the forefront of the development in various fields, including in the science of nuclear chemistry. This resulted in many applications of nuclear instruments NAA, PIXE, XRF, EPMA, AAS and others. PIXE is one of such analytical techniques gained popularity and applicability of the PIXE technique, especially in geochemistry has been gaining importance in recent times. When we observe the related scientific literature a number of researchers from earth sciences have established its applicability in the analysis of materials from geological sciences, these include rocks, minerals and ores etc. PIXE is giving results of geological materials for their major, minor, trace and REE concentrations. It has been an argument that some of the elements present in geological samples are purely determined or could not be determined at all by PIXE. This may be due to various reasons including the complexity of matrix in geological materials like high grade metamorphic rock, etc. Due to this challenge it is felt that a systematic investigation needs to be designed.

For this investigation, PIXE technique and it's limiting in analyzing, the geological material which is high grade metamorphic rock (Charnockites) belongs in to Eastern
Ghats Visakhapatnam of A.P state, India has been chosen. Another important factor for selecting this rock is based on the fact that the Charnockites of this area are well investigated and data are published in various scientific publications. This helped us to compare the data obtained by PIXE with that of published data to identify the elements which are poorly determined or could not be determined at all. Same samples are analyzed with other technique AAS and the results are authenticated by using an USGS reference material, Basalt. The reasons behind the poor performance of PIXE in case of certain elements have been tried to establish using the studies from the literature. The results are highly interesting and it is believed that the accuracy of problematic elements, especially from geological materials can be improved and it could be established the performance of PIXE with respect to different elements of the Charnockite samples.

The generation of characteristic X-ray from an element has an interest in the atomic physics. In the X-ray spectrometry, it was recognized that this method offers the possibility of multi elemental analysis even though complex matrices. The analysis of geological materials, comparison with results between the X-ray spectrometry and the conventional chemical methods found a good agreement. Particle Induced X-ray Emission (PIXE) showed that is 
relatively sensitive, multi elemental and non-destructive technique. PIXE introduced [21] at the Lund Institute of Technology in 1970 using $\mathrm{MeV}$ proton beams and highresolution $\mathrm{Si}(\mathrm{Li})$ detector.

Since the orbiting electrons of an atom must occupy discrete energy levels. The inner shell ionization of atoms in a specimen will causes by bombardment with ions of sufficient energy usually $\mathrm{MeV}$ protons. The inner shell vacancies replaced by outer shell electrons drop down, however, only certain transitions are allowed and X-ray of a characteristic energy of the element is emitted. An energy dispersive detector is used to record, measure these X-ray and the intensities are then converted to elemental concentrations. The elements in the target of composition are identified from the energies of the characteristic X-ray peaks. Also, quantity of an element in the target is determined from the intensity of its X-rays in the emission spectrum [22].

\subsection{PIXE Versus other Elemental Techniques}

PIXE can be used to analyze geological materials for a wide range of elements down to the levels of a few parts per million. The low background radiation in PIXE results in much higher sensitivity with detection limits. Both matrix and trace elements PIXE gives a higher signal to background ratio as compared to other techniques like EPMA. PIXE with micro beam spectrum 100 times better sensitive and micro beam has higher resolution as compared to Rutherford Back Scattering spectrometry. RBS is one of the quantitative depth profiling techniques available with typical accuracies and detection limits range from a few ppm for heavy elements to a few percent of light elements. RBS depth resolution is the order of $20-30 \mathrm{~nm}$, but can be as low as 2-3 nm near the surface of a sample.

PIXE and EDAX produce data for middle and high Z elements [43] which include the REE elements. A weakness of PIXE is the inaccessibility of light elements. While complimentary EMP technique help to fill this gap for major elements [44] providing routine major element data down to at least $\mathrm{Na}$, the lightest elements require nuclear reaction or recoil methods. EPMA provides much better results than standard SEM/EDS systems. Because of the internal properties of WDS, the general sensitivity, analysis of light elements and risks of erroneous interpretation of qualitative spectra are all superior with EPMA. Spectral resolution and detector dead time are much better than Energy Dispersive Spectroscopy. Using also protons, elements with $Z \leq 13$ can be analyzed by the NRA, PIGE or ERDA.

In PIGE, few $\mathrm{MeV}$ energy protons can penetrate the coulomb barrier on light elements and induce various nuclear reactions channels involve the emission of gamma rays. Detection of nuclear reaction induced gamma rays has enabled quantitative analysis methods to be developed. The lower coulomb barrier of light elements such as cross of reaction makes and particularly suitable for the analysis of light elements. Prompt $\gamma$-ray analysis (PIGE) offers in measuring light elements because, $\gamma$-rays from the different light elements can be easily distinguished by their energies. The advantage of PIGE over PIXE [9] is that highly energetic gamma rays suffer less absorption in passing through the detector's window and air.

The Scanning Electron Microscope is one of the instruments available for the analysis of the micro structural characteristics of solid objects. The SEM is routinely used to generate high-resolution images of shapes of objects and to show spatial variations in chemical compositions. Therefore the main asset of SEM is its high resolution when bulky objects are examined [32]. EDS detectors on SEM's cannot detect very light elements and many instruments cannot detect elements with atomic numbers less than 11 . Most SEMs use a solid state X-ray detector (EDS) and while these detectors are very fast and easy to utilize. They have a relatively poor energy resolution and sensitivity to the elements present in low abundances when compared to wavelength dispersive $\mathrm{X}$-ray detectors on most electron probe micro analyzers.

XRF has been choice for geologists for many years and used for routine, relatively non-destructive chemical analyses of geological materials. The background intensity distribution in PIXE and XRF spectra are opposite to each other due to its dependence on the excitation cross-section. The PIXE excitation and ionization cross-sections of various elements decreases with increasing atomic number, while in X-ray photon excitation, with the increase atomic number the cross-section increases. Therefore EDXRF is a better technique for the determination of elements with low energy X-ray lines which fall, especially in the range of $1-4 \mathrm{keV}$. Since detection limits are largely controlled by the background intensity, while PIXE is better for elements with atomic number greater than 50 which are relatively higher characteristic X-ray energies [3].

Both XRF and PIXE techniques can provide accurate and precise data when correctly applied to a suitable type of sample. Since X-rays are more penetrating than protons, the XRF technique samples a greater depth in a thick sample. However, the greater sampling depth requires more extensive corrections for inter-element and matrix effects. Although PIXE is superior to XRF because the entire range of elements in a sample can be excited by high-energy protons. Both have limitation of analyzing elements with $Z<11$ due to $\mathrm{Si}(\mathrm{Li})$ detector [14]. X-ray fluorescence spectrometer is an X-ray instrument, works on wavelengthdispersive spectroscopic principles that are like an electron microprobe (EPMA). However, an XRF cannot generally 
make analyses at the small spot sizes typical of EPMA work (2-5 microns). So it is typically used for bulk analyses of larger fractions of geological materials.

Neutron Activation Analysis is sensitive and therefore used to analyze for minor elements, which are present in very low concentrations. The method is especially for trace element analysis, but has limited use for light elements. It is not convenient for detection of some elements in geochemistry such as $\mathrm{Al}, \mathrm{Si}$ or $\mathrm{Pb}$. Particle-Induced X-ray Emission (PIXE) also at a low atomic number because, the low KX-ray fluorescence yields are strongly attenuated by the absorption edge of higher atomic number elements present in the sample [5]. So, PIXE and NAA are complements of PIGE when the identification of medium and heavy elements with high sensitivity is necessary in geological materials [11].

Laser ablation-inductively coupled plasma-mass spectrometry (LA-ICPMS) which is a rapidly developing analytical technique for the analyses of trace elements and isotopes. It plays an important role in advancing the study of earth science respect to micro geochemistry. ICP-MS is versatile techniques that can achieve LODs many orders of magnitude lower [36] than PIXE and XRF. LA-ICP-MS has been used in the spatial resolution analysis of elemental compositions compared to PIXE and rapid bulk analysis of whole-rock samples. In general, ICP-MS is determining many elements as quickly as or more so than XRF with very good accuracy. However, usually samples must be in liquid form, which often requires acid digestion and laborious sample preparation.

\subsection{PIXE and other Techniques in Geology}

In the geosciences research, using PIXE and complementary techniques, PIXE showed good results [26]. PIXE is well suited for the analysis of geological samples. In case of lightelement analysis, the complementary technique of particleinduced $\gamma$-ray emission (PIGE) used [25]. In thick target PIXE (TTPIXE) experiments, detection limits (MDL) for different matrices are identified and the poorest results were obtained in geological materials. PIXE versus other method, PIXE relies, fast nondestructive determination of all elements starting from $Z=18$ in the studied cases [17]. PIXE is very much suitable for quantitative elemental characterization in a various complex materials, especially in the range of middle $\mathrm{Z}$ elements [43]. The two techniques, Instrumental neutron activation analysis (INAA) and Proton induced X-ray emission (PIXE) was used to characterize geological samples. PIXE is more proficient in the analysis of media $Z$ elements. It was also verified from the result that elements with atomic number above ten are better analyzed with NAA [5].
When specimens are thick enough to stop the beam, it is clear that all the matrix (M) effect, accurate knowledge of the detector's line, shape and intrinsic efficiency at the low $\mathrm{X}$-ray energies, characteristic of the light elements that are so often the major elements are required. It also alleviates the problems of the deteriorating accuracy with which K-shell ionization cross sections and fluorescence yields are known as the atomic number falls from $Z=20$ to 10 . Another practical point regarding major-element analysis is that the high ionization cross sections result in very high yields of characteristic X-rays, working with low beam currents, large specimen-detector distance and handled by a $\mathrm{Si}(\mathrm{Li})$ detector [41].

The two techniques, EDXRF and PIXE were ability to perform rapid, simultaneous and nondestructive multielement analysis. Results obtained with the two techniques, above $94 \%$ showed to be in good agreement. It showed that the protons used in PIXE as the incident beam have a shorter penetration depth than the primary X-ray generated by the XRF tube [3]. The applications of techniques in geological materials such as PIXE, PIGE, NRA, RBS, ERDA, EBS etc. already successfully implemented in the laboratory. Each technique has its proper limitations to quantify elements in a target besides [42]. The combination of ( $\mu$-PIXE), (XRF), energy (SEM-EDS) and (XRD) techniques have been applied in the analyses of geological research. Also, obtained results must always be confirmed using the other analytical method [12]. In material analysis, the elemental concentration by using PIXE technique and compared data with other conventional methods like Atomic Absorption Spectrometry should be reviewed [33].

In this, an attempt is made to evaluate the performance of PIXE with respect to the geochemistry [31] of testing Charnockite rocks. The Charnockites obtained by PIXE for the elements tested have been authenticated by comparing these values with that of USGS standard material Basalt used. The analysis of USGS standard is shown each element has been compared with USGS. So, the following present the elements which are close to USGS standard elements having moderate errors and elements which are highly erroneous not detected by PIXE.

Another attempt is made to analyze the samples using Atomic Absorption photo spectrometer for PIXE evaluation [8] in high grade matrix composition. The same elements are reported and same standard also employed for a method of AAS. The data generated the AAS method has been used to compare the PIXE results [33] for its evaluation purpose. In this paragraph each element is considered in evaluating PIXE as per that element is concentrated. It is observed that the results obtained by AAS are close which already published data [35] [40] Charnockites in various journals [34] [39]. The reasons behind the poor performance of 
PIXE with respect to certain elements have been tried to explain [13]. The possibility of increasing accuracy of PIXE in analyzing samples of complex matrix like Charnockite has been discussed and suggestions were made.

Finally, an attempt is made to evaluate the performance of PIXE [17] with respect to the geochemistry of testing Charnockite samples. The Charnockites obtained by PIXE for the elements tested have been authenticated by comparing these values with that of USGS standard material Basalt used. Another attempt is made to analyze the samples using an atomic absorption photo, spectrometer and same elements are reported using the method of AAS and the same standard also employed for a method of AAS also.

Atomic Absorption Spectrophotometer, the sample is subjected to a high-energy thermal environment in order to produce excited state atoms. This environment can be provided by a flame or, more recently, plasma. However, since the excited state is unstable, the atoms spontaneously return to the "ground state" and emit light. The emission spectrum of an element consists of a collection of emission wavelengths called emission lines because of the discrete nature of the emitted wavelengths. The intensity of an emission line will increase as the number of excited atoms of the element increases.

\section{Methodology}

There are many techniques of ion beam accelerators, each using characteristic properties of each element (e.g. mass, charge of nucleus or electromagnetic radiation emitted or absorbed) to determine the composition, concentration and distribution of various elements in materials. In IBA, beams of charged particles are focused on a target resulting in various interactions between the atoms in the target and the charged particles in the beam. The interactions usually take the form of columbic interactions, excitations or nuclear reactions. The radiation that emerges from the interaction (scattered particles from columbic interactions, emitted photons from excited atoms and reaction products from nuclear reactions) is detected and their properties such as energy are measured yielding information on the composition of the target and distribution of the elements in the target.

\subsection{PIXE Methodology}

PIXE is a highly sensitive and non-destructive method for multi element analysis in variety geological materials [37] down to the levels of a few parts per million [15]. The samples chosen for analysis are collected from the central portion of a Charnockite hill near Visakhapatnam airport during a demolition operation for extension of the airport. A big lenticular mass compositionally different from the host Charnockite rock was observed in the central portion of the hill [23]. This body is believed to be the early crustal layer (possibly proto crust). Such samples are rare, PIXE technique is chosen for the trace elemental analysis of these rare samples.

The samples or rock, soil, sediments, clays etc. came under geology and their sample preparation is important in exploration of minerals and their concentration. Normally the samples in geology are called from different areas different conditions. Contaminating occurring the sample preparation processes serious threat for geological, chemical analysis. This is likely to occur during grinding and crushing and many created cross contaminating. This can be limited by careful cleaning and by pre-contaminating the appropriating with the sample to be crushed and grow contaminating during the grinding process can be elemental.

These experiments are carried out using $3 \mathrm{MV}$ pelletron accelerator facility at the Institute of physics, Bhubaneswar. Protons with $3 \mathrm{MeV}$ energy are used to excite the samples. The samples are mounted on an aluminum target holder (a ladder arrangement). Then the target holder is inserted into the scattering chamber and the irradiation is carried out in vacuum conditions. A collimated proton beam of $2 \mathrm{~mm}$ diameter is made to fall onto the sample. The beam current is kept at $20 \mathrm{nA}$, the samples on the target holder which are to be excited or positioned in this scattering chamber at an angle of $45^{\circ}$ with respect to the direction of the proton beam. The position of the sample relative to the beam direction is adjusted properly by viewing through a window provided in the scattering chamber. A high-resolution $\mathrm{Si}(\mathrm{Li})$ detector $(160 \mathrm{eV}$ FWHM at $5.9 \mathrm{keV}$ energy) is employed in the present experiments to record the X-ray spectrum. The detector is placed at an angle of $90^{\circ}$ with respect to the beam direction. The output of the $\mathrm{Si}(\mathrm{Li})$ detector is a coupled to data acquisition system, which records the X-ray spectrum. The spectrum of each sample is recorded for a sufficiently long time to ensure good statistics. During the irradiation of each sample the charge collected, and the average beam current is noted as shown in Fig. 1.

The Guelph PIXE (GUPIX) software package [27] is used to analyze the spectra utilizing a standard Marquardt non-linear least square fitting procedure. This package provision is to identify different elements present in the sample and to estimate their relative intensities. Using this GUPIX software package the X-ray intensities of different elements are converted into the respective concentrations using a standardized technique involving fundamental parameters, pre-determined instrument constants and input parameters such as solid angle, charge collected etc. Comparing the concentrations of Yttrium obtained in the present work with the known concentration of Yttrium added to the sample, the reliability of the input parameters 
is checked. To assure the reliability of experimental system and other parameters, in the same experimental conditions, the PIXE spectrum is recorded with NIST certified reference material and the relative concentrations of different elements are estimated using GUPIX software package. The relative concentrations of different elements, thus obtained in the present experiment for the above standard samples are compared with the certified concentrations supplied by NIST. Good agreement within experimental uncertainties is observed and this shows the reliability of the present experimental system and use of GUPIX software package in the data analysis.

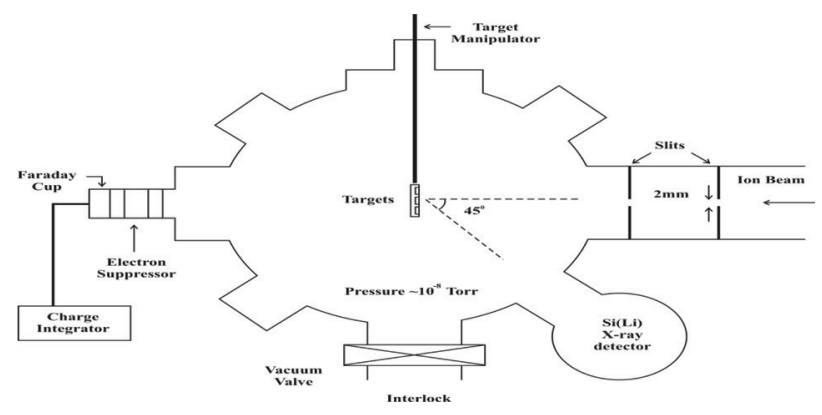

Figure 1: Schematic diagram of the PIXE arrangement.

Table 1: PIXE spectrum is recorded with NIST certified reference material-Apple Leaves-1515.

\begin{tabular}{lll}
\hline \multirow{2}{*}{ Element } & \multicolumn{2}{c}{ Concentration (ppm) } \\
& Certified values & Measured values (PIXE) \\
\hline$K$ & $1.48 \pm 0.05$ & $1.60 \pm 0.02$ \\
$\mathrm{Ca}$ & $1.615 \pm 0.26$ & $1.53 \pm 0.02$ \\
$\mathrm{Mn}$ & $48.5 \pm 2.4$ & $54.0 \pm 3.0$ \\
$\mathrm{Fe}$ & $88.1 \pm 4.5$ & $83.0 \pm 5.0$ \\
$\mathrm{Cu}$ & $5.3 \pm 0.4$ & $5.60 \pm 0.24$ \\
$\mathrm{Zn}$ & $12.9 \pm 0.7$ & $12.5 \pm 0.03$ \\
$\mathrm{Se}$ & $0.06 \pm 0.01$ & $0.05 \pm 0.009$ \\
$\mathrm{Rb}$ & $9.3 \pm 1.0$ & $10.2 \pm 1.50$ \\
$\mathrm{~Pb}$ & $0.54 \pm 0.08$ & $0.47 \pm 0.02$ \\
\hline
\end{tabular}

\subsection{AAS Methodology}

In AAS [4] the light source should produce a narrow spectrum with little background noise, stable and have enough intensity. Hollow cathode lamp is most widely used as a light source. Inside the lamp, the cathode is coated with a metal of analyst to be analyzed. For instance, if magnesium is to be analyzed from the sample, a cathode coated with magnesium is used. Similarly, for all the other elements like $\mathrm{Na}, \mathrm{Ca}, \mathrm{K}, \mathrm{Zn}$, etc. analysis respective metal coated cathodes are used in the lamp. The lamp is filled with an inert gas like argon or neon which is ionized by an electric arc. The ions get attracted toward cathodes and strike it leading to excitation of metal ions. This leads to the emission of radiation with a characteristic wavelength of analyte metal.

The advantages of Hollow cathode lamp are that it provides radiation with a bandwidth of 0.001 to $0.01 \mathrm{~nm}$. Use of other methods like monochromatic gives radiation with a bandwidth of $1 \mathrm{~nm}$. So, these lamps give highly specific radiation. The disadvantage of this hollow cathode lamp is that for every metal different cathode lamp must be employed. Electrode-less discharge lamp is less conventional in regular use, but is essential of determination of arsenic and selenium. A bulb containing an element of interest (with argon gas) is present in the lamp. This element is excited using microwave energy or radio frequency energy. Sample container is a beaker-like a container of the sample which is placed below the burner preferably. A capillary tube drains the sample to the tip of the burner. The burner (atomizer) here the sample from the capillary rises to the tip of the burner. Here it is burns with the flame and flame is produced by a fuel and oxidant combination. The sample after evaporation leaves a fine residue of neutral atoms.

Fuel and oxidant are a very important, if the heat produced is not enough, then the sample doesn't form neutral atoms and the heat of the burner is more, the sample molecules may ionize instead of forming atoms. So, both are undesirable and hence a proper combination of fuels and oxidant are to be used to produce recommended temperatures. Commonly used flues include propane, hydrogen, and acetylene and oxidants are mostly air or oxygen. Monochromatic discussed before, elements have specific absorption lines. But some elements also have secondary absorption lines. Further, there is also emitted from the lamp and the flame. Hence, we need to isolate the desired spectral line for the measurement of absorption. To achieve this monochromatic which can filter and provide a resolution of $<1 \mathrm{~nm}$ is employed.

The detector is a part of the instrument detects the intensity of radiation absorbed by the elements. The detector consists of a photomultiplier tube or simple photocell. The current or potential recorded for the sample absorption is recorded on computer and then analyzed. It displays the absorbance at a specific wavelength as shown in Fig. 2.

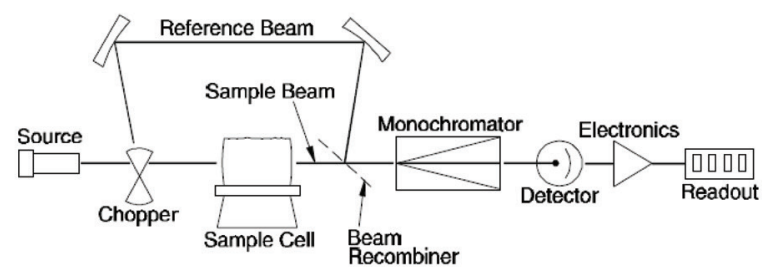

Figure 2: Schematic diagram of Atomic Absorption Spectrometer. 


\section{Results}

The PIXE spectrum of the geological samples G1 to G7 locations collected from the interior of the Charnockite rock recorded by $\mathrm{Si}(\mathrm{Li})$ detector. These concentrations are presented with errors in Table-3 assuming standard deviation values (n) $=7$ and BDL (Below Detection Limit). In this an attempt is made to evaluate the performance of PIXE with respect to the geochemistry of tested Charnockite samples. The Charnockites obtained by PIXE for the elements testing have been authenticated by comparing these values with that of USGS standard material Basalt used. The analysis of USGS standard, each element has been compared with USGS. So, the following table presents the elements which are close to USGS standard elements having moderate errors and elements which are highly erroneous not detected.
Another attempt is made to analyze the samples using an atomic absorption photo spectrometer and same elements are reported using the method of AAS and the same standard also employed for a method of AAS also. The data generated the AAS method has been used to compare the PIXE results [33] for its evaluation purpose. In this paragraph, each element is considered in evaluating PIXE as per that element is concentrated. It is observed that the results obtained by AAS are close which already published [35] [40] data on Charnockites in various journals [34] [39]. The reasons behind the poor performance of PIXE with respect to certain elements have been tried to explain [13]. The possibility of increasing accuracy of PIXE in analyzing samples of complex matrix like Charnockite has been discussed and suggestions are made.
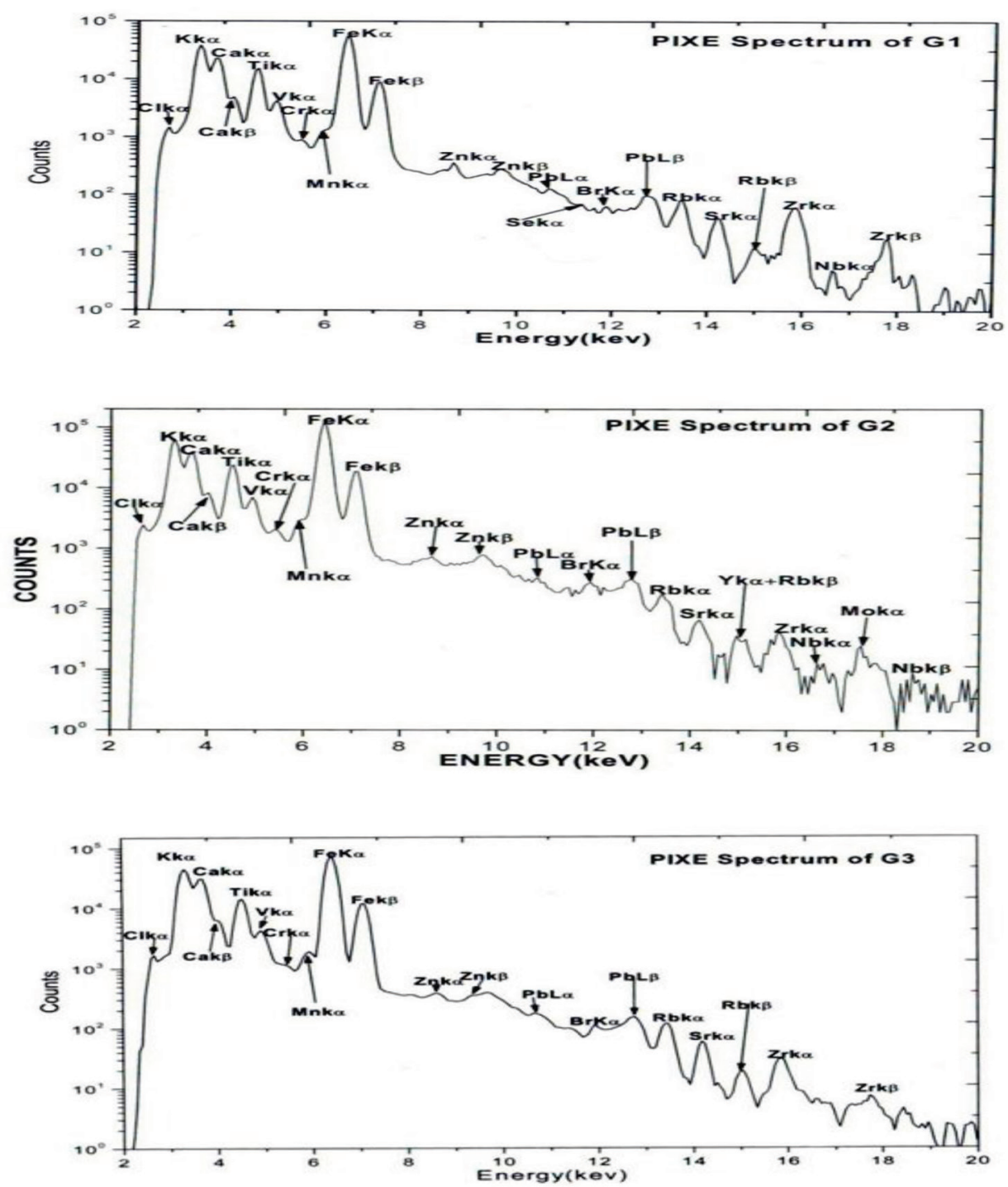

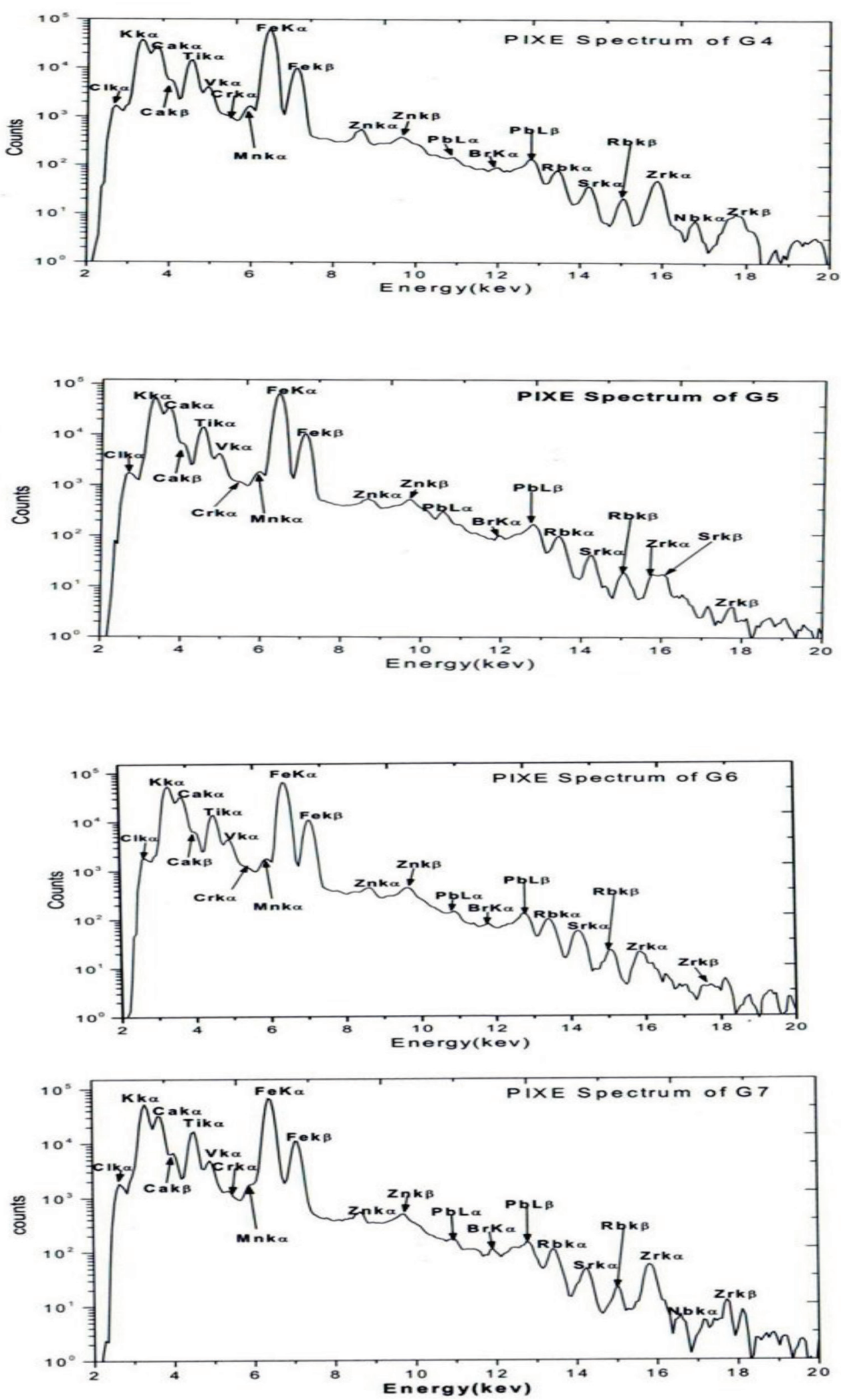

(Spectrums of PIXE of few samples in each category from G1 to G7) 
The PIXE spectrum of the geological samples G1 to G7 locations collected from the interior of the Charnockite rock recorded by $\mathrm{Si}(\mathrm{Li})$ detector. The concentrations in ppm of these various elements in each sample were determined using the GUPIX software. These concentrations are presented with errors in Table-3. To assure the reliability of experimental system and other parameters, in the same experimental conditions, the PIXE spectrum is recorded with certified USGS reference material Basalt Hawaiian Volcanic Observatory (BHVO)-2 and verified by PIXE shown in Table-2, 3 the relative concentrations of different elements are estimated, excellent accuracy precision and agreement between reported and analyzed abundances were obtained in certain elements and these results are verified by other technique AAS as shown in Table-2, 4.

Table 2: USGS Standard reference material (verified by PIXE and AAS).

\begin{tabular}{|c|c|c|c|c|c|c|}
\hline Element & Certified Values ppm & \pm & $\begin{array}{l}\text { Measured value ppm } \\
\text { (PIXE) }\end{array}$ & \pm & $\begin{array}{l}\text { Measured value ppm } \\
\text { (AAS) }\end{array}$ & \pm \\
\hline$A l$ & 71600 & 800 & - & & 70208 & 787 \\
\hline$C a$ & 81700 & 1200 & 7834.26 & 93 & 80232 & 1172 \\
\hline $\mathrm{Fe}$ & 86300 & 400 & 7982 & 74 & 86907 & 1421 \\
\hline$K$ & 64300 & 100 & 9830 & 80 & 65103 & 96 \\
\hline$M g$ & 43600 & 700 & - & - & 43864 & 711 \\
\hline$N a$ & 16400 & 600 & - & - & 16104 & 589 \\
\hline$P$ & 61200 & 100 & - & - & 60352 & 91 \\
\hline$S i$ & 233000 & 3000 & - & - & 230724 & 2936 \\
\hline$T i$ & 16300 & 2000 & 3286 & 64 & 15173 & 1890 \\
\hline$B a$ & 130 & 13 & - & - & 126 & 12 \\
\hline$C e$ & 38 & 2 & - & -- & - & - \\
\hline$L a$ & 15 & 1 & - & - & - & - \\
\hline Co & 45 & 3 & 10.5 & 1 & 44 & 3 \\
\hline $\mathrm{Cr}$ & 280 & 19 & 295.2 & 25 & 290.08 & 21 \\
\hline$C u$ & 127 & 7 & 133.23 & 10.14 & 135.63 & 8 \\
\hline$G a$ & 21.7 & 0.9 & 22.52 & 2.6 & 22.52 & 2.6 \\
\hline$H f$ & 4.1 & 0.3 & - & - & - & - \\
\hline
\end{tabular}

Table 3: Analytical results of all geological samples (PIXE).

\begin{tabular}{lllllllll}
\hline S.NO & Element & G1 & G2 & G3 & G4 & G5 & G6 & G7 \\
\hline 1 & $\mathrm{Cl}$ & $394.1 \pm 16.5$ & $399.6 \pm 17.1$ & $379 \pm 16.5$ & $403.5 \pm 19.5$ & $546.9 \pm 23.5$ & $383.7 \pm 16.7$ & $462.6 \pm 20.6$ \\
2 & $\mathrm{~K}$ & $4080 \pm 28.2$ & $4187 \pm 25.1$ & $4148 \pm 26.1$ & $4246 \pm 29.3$ & $6699 \pm 40.2$ & $5458 \pm 27.1$ & $5393 \pm 33.4$ \\
3 & $\mathrm{Ca}$ & $2229 \pm 25.9$ & $2281 \pm 22.8$ & $2637 \pm 25.6$ & $2754 \pm 28.1$ & $4120 \pm 23.5$ & $2544 \pm 26.2$ & $3091 \pm 32.1$ \\
4 & $\mathrm{Ti}$ & $1394 \pm 11.6$ & $1271 \pm 9.3$ & $1109 \pm 9.3$ & $13.67 \pm 11.3$ & $1590 \pm 13.8$ & $1044 \pm 9.1$ & $1510 \pm 12.4$ \\
5 & $\mathrm{~V}$ & $17.92 \pm 4.8$ & $23.69 \pm 4.1$ & $7.85 \pm 4.0$ & $\mathrm{BDL}$ & $37.78 \pm 6.0$ & $10.79 \pm 4.0$ & $11.55 \pm 12.4$ \\
6 & $\mathrm{Cr}$ & $16.63 \pm 2.3$ & $38.53 \pm 2.1$ & $15.16 \pm 2.1$ & $16.93 \pm 2.5$ & $17.71 \pm 3.1$ & $9.118 \pm 2.1$ & $14.13 \pm 2.6$ \\
7 & $\mathrm{Mn}$ & $18.62 \pm 3.9$ & $34.71 \pm 3.7$ & $34.31 \pm 3.7$ & $33.68 \pm 4.1$ & $47.43 \pm 5.3$ & $27.36 \pm 3.5$ & $27.03 \pm 4.5$ \\
8 & $\mathrm{Fe}$ & $5200 \pm 20.3$ & $6575 \pm 21.0$ & $5649 \pm 19.8$ & $5838 \pm 22.2$ & $7325 \pm 26.4$ & $4905 \pm 17.7$ & $6238 \pm 23.1$
\end{tabular}




$\begin{array}{lllllllll}9 & \mathrm{Ni} & 10.96 \pm 3.7 & 11.43 \pm 3.7 & 10.06 \pm 3.39 & 8.94 \pm 3.92 & 28.29 \pm 5.02 & 10.11 \pm 3.1644 & 16.5 \pm 4.3692 \\ 10 & \mathrm{Cu} & \mathrm{BDL} & \mathrm{BDL} & 6.1 \pm 2.7 & \mathrm{BDL} & \mathrm{BDL} & \mathrm{BDL} & 8.717 \pm 3.47 \\ 11 & \mathrm{Zn} & 9.147 \pm 3.3 & 18.21 \pm 3.5 & 14.23 \pm 3.0 & 14.41 \pm 3.5 & 11.96 . \pm 4.6 & 24.73 \pm 2.9 & 4.29 \pm 2.0 \\ 12 & \mathrm{Se} & 6.3 \pm 65 \pm 2.5 & \mathrm{BDL} & \mathrm{BDL} & 0.9499 \pm 1.7 & \mathrm{BDL} & \mathrm{BDL} & \mathrm{BDL} \\ 13 & \mathrm{Br} & 4 \pm 2.2 & 12.17 \pm 2.93 & 11.82 \pm 2.85 & 13.47 \pm 6.2 & 10.32 \pm 4.031 & 8.61 \pm 2.455 & 9.08 \pm 3.503 \\ 14 & \mathrm{Rb} & 48.87 \pm 6.0 & 42.08 \pm 6.1 & 62.73 \pm 6.0 & 34.71 \pm 6.2 & 56.14 \pm 7.9 & 34.58 \pm 5.3 & 52.46 \pm 7.1 \\ 15 & \mathrm{Sr} & 38.5 \pm 5.4 & 28.6 \pm 4.6 & 44.61 \pm 4.9 & 27.65 \pm 5.2 & 38.02 \pm 6.5 & 33.91 \pm 4.9 & 35.53 \pm 6.1 \\ 16 & \mathrm{Y} & \mathrm{BDL} & 12.64 \pm 4.5 & \mathrm{BDL} & 18.13 \pm 5.0 & \mathrm{BDL} & \mathrm{BDL} & \mathrm{BDL} \\ 17 & \mathrm{Zr} & 95.91 \pm 9.8 & 20.86 \pm 6.0 & 23.6 \pm 6.1 & 63.7 \pm 8.7 & 11.44 \pm 7.0 & 12.16 \pm 5.0 & 77.82 \pm 9.3 \\ 18 & \mathrm{Nb} & 7.035 \pm 3.1 & 9.812 \pm 3.9 & \mathrm{BDL} & 6.09 \pm 3.29 & \mathrm{BDL} & \mathrm{BDL} & \mathrm{BDL} \pm 6 . \pm 6 . \\ 19 & \mathrm{Mo} & \mathrm{BDL} & 24.34 \pm 6.3 & \mathrm{BDL} & 10.84 \pm 4.04 & \mathrm{BDL} & \mathrm{BDL} & \mathrm{BDL} \\ 20 & \mathrm{Ru} & \mathrm{BDL} & \mathrm{BDL} & \mathrm{BDL} & \mathrm{BDL} & \mathrm{BDL} & 9.977 \pm 3.59 & \mathrm{BDL} \\ 21 & \mathrm{Ag} & \mathrm{BDL} & 12.36 \pm 9.0 & \mathrm{BDL} & \mathrm{BDL} & \mathrm{BDL} & \mathrm{BDL} & \mathrm{BDL}\end{array}$

Table 4: Analytical results of all geological samples (AAS).

\begin{tabular}{|c|c|c|c|c|c|c|c|}
\hline Element & G11 & G21 & G31 & G41 & G51 & G61 & G71 \\
\hline $\mathrm{Na}$ & 23483 & 15561 & 22300 & 23718 & 26679 & 25505 & 25306 \\
\hline Mg & 20568 & 16467 & 20026 & 20209 & 20501 & 24063 & 17546 \\
\hline Al & 89081 & 90776 & 87760 & 96543 & 88132 & 89302 & 90105 \\
\hline Si & 260631 & 274683 & 265398 & 269366 & 265905 & 262318 & 261506 \\
\hline $\mathbf{P}$ & 1367 & 1402 & 916 & 1103 & 1231 & 1450 & 1582 \\
\hline $\mathrm{Cl}$ & - & - & - & - & - & - & - \\
\hline $\mathbf{K}$ & 24813 & 29466 & 27052 & 25739 & 9268 & 11374 & 13908 \\
\hline $\mathrm{Ca}$ & 33709 & 28918 & 30776 & 29412 & 29418 & 36403 & 39305 \\
\hline $\mathbf{T i}$ & 7001 & 7403 & 7606 & 7842 & 6582 & 7409 & 7205 \\
\hline $\mathbf{V}$ & 127 & 125 & 136 & 129 & 143 & 137 & 126 \\
\hline $\mathrm{Cr}$ & 38 & 34 & 39 & 33 & 38 & 31 & 39 \\
\hline Mn & 2023 & 2706 & 1855 & 1784 & 1548 & 2202 & 3011 \\
\hline $\mathrm{Fe}$ & 87176 & 69983 & 88511 & 71342 & 90979 & 86904 & 87202 \\
\hline Co & 8 & 10 & 7 & 9 & 7 & 11 & 7 \\
\hline $\mathrm{Ni}$ & 38 & 34 & 42 & 45 & 39 & 37 & 42 \\
\hline $\mathrm{Cu}$ & 8.8 & 12.8 & 11.9 & 9.2 & 6.6 & 8.6 & 11.1 \\
\hline $\mathrm{Zn}$ & 11.3 & 12.3 & 9.3 & 15.4 & 10.6 & 10.9 & 9.3 \\
\hline $\mathrm{Se}$ & 6.3 & 7 & 4 & 6 & 7.4 & 3.9 & 5 \\
\hline $\mathrm{Br}$ & - & - & - & - & - & - & - \\
\hline $\mathbf{R b}$ & 60.8 & 70.1 & 74.6 & 89 & 82.9 & 77.5 & 71 \\
\hline
\end{tabular}




\begin{tabular}{llllllll}
$\mathbf{S r}$ & 144 & 132 & 143 & 126 & 119 & 128 & 148 \\
$\mathbf{Y}$ & 56 & 39.5 & 47.3 & 49.1 & 45.8 & 63.2 & 46.2 \\
$\mathbf{Z r}$ & 194.1 & 189.6 & 198.9 & 190.6 & 189 & 12.1 & 12 \\
$\mathbf{N b}$ & 15.9 & 14.5 & 13.1 & 12.1 & 10.9 & 12.9 & 12.6 \\
$\mathbf{M o}$ & 5.8 & 6 & 6 & 5.3 & 8 & 8 & 6 \\
$\mathbf{R u}$ & 4.9 & 5.9 & 4.3 & 4.2 & 4 & 6 & 4.4 \\
$\mathbf{A g}$ & 10 & 4.2 & 4.1 & 4.2 & 7 & 5 & 4 \\
$\mathbf{P b}$ & 29.3 & 27.9 & 31.3 & 32.4 & 28 & 28 & 32.9 \\
$\mathbf{B a}$ & 852 & 843 & 839 & 858 & 823 & 857 & 819 \\
\hline
\end{tabular}

Table 5: Elemental analysis of Charnockite samples (AAS).

\begin{tabular}{llllllll}
\hline Element (Wt.\%) & G11 & G21 & G31 & G41 & G51 & G61 & G71 \\
\hline $\mathbf{S i}$ & 26.063 & 27.68 & 26.539 & 26.936 & 26.590 & 26.23 & 26.15 \\
$\mathbf{A l}$ & 8.908 & 9.077 & 8.776 & 9.654 & 8.813 & 8.93 & 9.01 \\
$\mathbf{T i}$ & 0.7 & 0.940 & 0.760 & 0.784 & 0.658 & 0.74 & 0.72 \\
$\mathbf{F e}$ (total) & 8.717 & 6.99 & 8.851 & 7.134 & 9.097 & 7.88 & 8.72 \\
$\mathbf{M g}$ & 2.056 & 1.646 & 2.002 & 2.020 & 2.050 & 2.406 & 1.754 \\
$\mathbf{M n}$ & 0.202 & 0.270 & 0.185 & 0.178 & 0.154 & 0.22 & 0.301 \\
$\mathbf{K}$ & 2.481 & 2.946 & 2.7058 & 2.573 & 0.9268 & 1.137 & 1.39 \\
$\mathbf{C a}$ & 3.37 & 2.891 & 3.027 & 2.941 & 2.949 & 3.648 & 3.93 \\
$\mathbf{N a}$ & 2.346 & 1.556 & 2.230 & 2.371 & 2.667 & 2.55 & 2.53 \\
$\mathbf{P}$ & 0.136 & 0.140 & 0.092 & 0.110 & 0.123 & 0.145 & 0.158 \\
\hline
\end{tabular}

Table 6: Conversion of elemental composition into oxides (AAS).

\begin{tabular}{llllllll}
\hline Element (wt.\%) & G11 & G21 & G31 & G41 & G51 & G61 & G71 \\
& & & & & & & \\
\hline Sio2 & 55.81 & 58.82 & 56.83 & 57.68 & 56.94 & 56.17 & 56.01 \\
Al2o3 & 16.84 & 17.16 & 16.59 & 18.25 & 16.66 & 16.89 & 17.05 \\
Tio2 & 1.17 & 1.57 & 1.27 & 1.31 & 1.10 & 1.24 & 1.21 \\
Fe2o3 & 1.65 & 1.39 & 1.72 & 1.094 & 1.289 & 0.81 & 0.82 \\
Feo & 9.74 & 7.77 & 9.85 & 7.78 & 10.05 & 10.15 & 10.18 \\
Mgo & 3.41 & 2.73 & 3.321 & 3.35 & 3.42 & 3.51 & 2.91 \\
Mno & 0.262 & 0.35 & 0.241 & 0.23 & 0.20 & 0.29 & 0.39 \\
K2o & 2.99 & 3.55 & 3.26 & 3.10 & 1.16 & 1.37 & 1.67 \\
Cao & 4.72 & 4.05 & 4.31 & 4.12 & 5.42 & 5.11 & 5.31 \\
Na2o & 3.17 & 2.10 & 3.01 & 3.20 & 3.60 & 3.45 & 3.42 \\
P2o5 & 0.31 & 0.32 & 0.21 & 0.25 & 0.28 & 0.33 & 0.36 \\
Total & 100.078 & 99.81 & 100.423 & 100.84 & 100.58 & 100.57 & 100.27 \\
\hline
\end{tabular}




\section{Discussions}

In this chapter an attempt is made to interpret the geochemical [15] data (Table 3) of the Charnockite samples. The results describe to the evaluation of PIXE by using the samples of Charnockites where the same samples are analyzed by PIXE and AAS (Table 3, 4). The results (Table 5, 6) are authenticated by the published data on Charnockite of the study area [35] [40] as well as Charnockite from sample areas based on the comparison the finalized data on the Charnockite samples have been arrived the final data and presented (Table-6) with percentage. Using this data, the Charnockite hill from where the samples are collected have been attempted to understand the chemical nature followed by genetic implications. The reasons behind the poor performance of PIXE with respect to certain elements have been tried to explain.

Accuracy, precision, detection limits [13] and limitations of measurements of all elements present in the Basalt reference material and Precambrian Charnockites by PIXE was studied. The effect of spot size of the proton beam of energy $3 \mathrm{MeV}$ with $\mathrm{Si}(\mathrm{Li})$ detector on accuracy, precision, limitations and its evaluation was investigated. The attractiveness of non-destructive methods and the ability to perform simultaneous multi elemental determinations has led to an extensive application [6] of accurate, precise and sensitive atomic and nuclear analytical technique such as PIXE in highly matrix rock. Generally, PIXE method offers maximum sensitivity when atomic number $\mathrm{Z}$ of a detected element roughly is in the range 20 to 40 , but in this investigation of Charnockites, the elements identified from $17(\mathrm{Cl})$ to $47(\mathrm{Ag})$ and $82(\mathrm{~Pb})$ were studied.

In this PIXE investigation, the detection limit is decreased despite the higher ionization cross section for light elements, since the excitation and ionization cross-sections of various elements decrease with increasing atomic number in PIXE analysis. So, the limitation of the PIXE investigated in the evaluation method is that the light elements $\mathrm{Na}, \mathrm{Mg}$, $\mathrm{Al}, \mathrm{Si}$ and $\mathrm{F}$ at $3 \mathrm{MeV}$ protons in Basalt and Charnockite samples shown (Table 2, 3,4). This is because of decreasing fluorescence yield, increasing bremsstrahlung background [19] [30] for lighter elements and increasing absorption in detector window.

Since detection limits are controlled by the background intensity. EDXRF is a better technique for the determination of elements with low energy X-ray lines, especially in the range of $1-4 \mathrm{keV}$ because, in $\mathrm{X}$-ray photon excitation, the cross-section increases with the increase atomic number. Since $\gamma$-rays from the different light elements can be easily distinguished by their energies, therefore Prompt $\gamma$-ray analysis (PIGE) offers an alternative in measuring light elements which are not detected by PIXE. Using also protons, elements with low $\mathrm{Z}$ can be analyzed by the NRA, PIGE or ERDA, while PIXE is better for elements with relatively higher characteristic X-ray energies for elements with atomic number 20-47 in Charnockite composition at $3 \mathrm{MeV}$ PIXE (spectrum 1-7).

Since PIXE at $3 \mathrm{MeV}$, the light elements have not been detected, therefore possibly low energy particle PIXE [20] able to detect the above elements. PIXE [18] is a nondestructive multi elemental technique allowing to determine concentration of elements with $\mathrm{Z}>11$ but in the present study is that $Z>16$ at $3 \mathrm{MeV}$ proton energy in Charnockite. Hence PIXE with low energy protons possible to success in fields of geology with detection limits in the order of ppm. PIXE failed in the situation [38] where the species of interest has a low atomic number because the low $\mathrm{K}$ X-ray fluorescence yields are strongly attenuated by the absorption edge of higher atomic number elements present in the Charnockite matrix composition (Table 3, 4). Also, the element $\mathrm{K}$ and $\mathrm{Ca}$ escape peaks in the spectrum of Charnockites, interfere with X-ray lines of $\mathrm{Al}, \mathrm{Si}, \mathrm{Na}$ and $\mathrm{Mg}$ in $\mathrm{Si}$ (Li) detector (spectrum 1-7).

However, the characteristic X-ray cross section decreases rapidly as the proton energy decreases, particularly at energies less than $3 \mathrm{MeV}$ for the detection of low $\mathrm{Z}$ elements. The energy loss at the target cannot be neglected in comparison with Incident energy. Therefore, at low energy of proton a very thin target for low $\mathrm{Z}$ elements in Charnockite is required for accurate quantitative analysis. As an outcome of this work we can apply $3 \mathrm{MeV}$-energy PIXE in a quantitative manner to Charnockite research topic particularly in case of major and trace elements. In addition, the experiments to clarify the $\mathrm{K} \mathrm{X}$-ray cross sections at $3 \mathrm{MeV}$ proton energies atomic number $(Z=17)$ elements to the atomic number $(Z=47)$ elements would be desirable and for high $\mathrm{Z}$ elements like $\mathrm{Pb} \mathrm{L}$ X-ray cross sections would be desirable from spectrum analysis (spectrum 1-7).

Determination of REE in Charnockite [40] is a very important but hard to tackle because in this PIXE, the L $\mathrm{X}$-rays energies from 4-9 $\mathrm{keV}$ strongly overlap with $\mathrm{K}$ $\mathrm{X}$-rays energies of light elements in Charnockite matrix composition (spectrum 1-7). The quantification of REE by PIXE with $3 \mathrm{MeV}$ becomes very difficult and inaccurate as a result of the needed complex spectrum deconvolution. In fact, in this work context of REE in geological sample's composition; L X-ray used and concluded that PIXE with $3 \mathrm{MeV}$ is limited for REE. Rare earth elements have very high thermal neutron cross sections and NAA is usually the first choice for the determination of REEs in a trace elements analysis. From this it results that by coupling PIXE for middle $\mathrm{Z}$ elements with PIGE for low $\mathrm{Z}$ elements and NAA for REE methods, a very good overall picture of the elemental composition of a Charnockites may be obtained. 
In this study, $\mathrm{Si}(\mathrm{Li})$ detector was unable to find the REE elements in composition. To overcome this problem, the use of large Ge detection to detect the L X-ray of REE was attempted. But due to large dimensions, a large Compton background is present which degrades the detection limits in the high X-ray energy region. Small Ge detection represents an improvement relative to this problem. But their overall size is still significative to this problem. But their overall crystals reduced solid angle. The $\mathrm{Cd}$ Te detects have average atomic numbers of 50 allow the construction of small detection [7]. This possible overcoming the Compton problem at the same time as it solves solid angle problems since they can be placed very close to the sample. The $\mathrm{Cd} \mathrm{Te}$ detectors are thus a good possibility for high energy PIXE for better resolution of low $\mathrm{Z}$ elements $\mathrm{L} \mathrm{X}$-rays and high $\mathrm{Z}$ elements K X-rays of REE in Charnockites. Micro PIXE [1] is also an alternative experimental setup, diameter of proton beams drastically decreased, and then the resolution of matrix elements can be minimized.

In Charnockites, high energy PIXE is suitable to detect REE, when compared to present $3 \mathrm{MeV}$ PIXE since production cross section increases with proton incident energy. This additional information can help analyze the complex data in high grade metamorphic rock. For heavy elements in REE can be detected as per as few millimetres deep inside the sample. So, for high proton, the energy loss, the energy straggling and angular diffusion, low no disturbance of the beam. So, data analysis is simple to the slow evolution of the X-ray production cross section and low straggling energy induces more accurate results.

The use K X-ray of could be a solution, but at that for REE in Charnockites detection is possible by using high energy PIXE [16] with the suitable high efficiency detector. The main components of the continuous background in the X-rays energy spectrum of high energy PIXE analysis are quasi free electron bremsstrahlung and second electron bremsstrahlung. The maximum energies of these as the projectile energy increases, the character X-ray production cross section becomes too large in this projectile energy region. So, the detection limit of high energy proton PIXE is not expected to be significantly larger than low energy proton.

\subsection{Detection Limit}

Since the very low number of elements are available in the geological compositions, high sensitivity of the system is required for analysis. From sensitivity point of view, PIXE has certain superiority, moreover the bremsstrahlung produced in PIXE is a secondary effect where as in case of Electron Microprobes and XRF it is primary contributor. The principal source of proton back ground against which the character X-rays of elemental constituents must be distinguished and hence is also the principal determinant of detection limits. Compared to electron based X-ray analytical techniques such as energy dispersive spectroscopy (EDS) and EPMA, PIXE offers better peak to noise ratios. The possible advantages it presents, such as low background radiation, good sensitivity for light elements, and lower secondary excitation in thick targets.

The generation of X-rays by $3 \mathrm{MeV}$ PIXE [38] and previous Electron Probe Micro Analysis (EPMA) [40] $\mathrm{keV}$ energy electrons are quantitatively similar in analyses. However, the bremsstrahlung background is low in PIXE, which is the primary determinant of detection limits of the abundances of many elements from $\mathrm{Cl}$ to $\mathrm{Pb}$ down to parts per million in Basalt and Charnockites. The detection limit of geological sample, for example Se detected in the above Table-3 by PIXE analysis is below 1 microgram/gram which indicates the ability of trace element analysis. The detection limit of $\mathrm{Se}$ is $0.9 \mathrm{ppm}$, which represents very good sensitivity of the system. Trace element less than $0.0001 \%$ wt. analysis is possible in case of Charnockite composition in the investigation. This confirms the usefulness of PIXE analysis in the $3 \mathrm{MeV}$ energy regimes for the analysis of Precambrian Charnockites.

The detection limit changes from $1 \mathrm{ppm}$ for proton energies in the range $3 \mathrm{MeV}$, i.e. elements in the range $Z=17$ to $Z=82$ in case of Charnockites. The detection limits in the $3 \mathrm{MeV}$ rapidly increases an increase in atomic number in the region of $Z=30-47$. This behavior can be explained by the decrease in characteristic $\mathrm{X}$-ray production cross section due to the coulomb deflection and the binding energy effects. A closer study of Charnockite samples of the spectrums given an important that the optimum proton energy should lie somewhere $3 \mathrm{MeV}$ for radiation $\mathrm{K} \alpha$ giving us low detection limit both low and high $\mathrm{Z}$ region from spectrum 1-7. Since the detection limits of $\mathrm{K} \mathrm{X}$-ray measurement and L X-ray measurement coincide each together at the atomic number near $Z=50$, this analysis was performed for $K X$-ray for the elements with $\mathrm{Z}$ below 50 , and for $\mathrm{L} \mathrm{X}$-ray for the elements with $Z$ above 50 [24].

The low detection values for different elements in this investigation at media $\mathrm{Z}$ elements reflect the general characteristics of the PIXE spectra. The background dominated at lower energies, by the bremsstrahlung of the secondary electrons, and the experimental conditions like detection efficiency and sample matrix and thickness explained in this study [2].

\section{Resolution}

In this work of analysis, the overlaps in the case of Charnockite samples are: $\mathrm{Ni}-\mathrm{K} \alpha$ and $\mathrm{Co}-\mathrm{K} \beta$; $\mathrm{Fe}-\mathrm{K} \alpha$ and $\mathrm{Mn}-\mathrm{K} \beta ; \mathrm{Cu}-\mathrm{K} \alpha$ and $\mathrm{Zn}-\mathrm{K} \beta ; \mathrm{Y}-\mathrm{K} \alpha$ and $\mathrm{Rb}-\mathrm{K} \beta$ 
from spetrum 1-7. The corrections have to be made for quantitative analysis of element in concentration using known $\mathrm{K} \alpha / \mathrm{K} \beta$ ratios for its evaluation. The elements in the above Charnockite composition with $\mathrm{Z} \leq 30$ an interference is encountered between the $\mathrm{K} \alpha(\mathrm{Z}+1) \mathrm{X}$-ray and the $\mathrm{K} \beta(\mathrm{Z})$ $\mathrm{X}$-ray, which have virtually the same energy. In addition to that PIXE analysis, the error in concentrations due to Ti-Ko and $\mathrm{Fe}-\mathrm{K} \alpha$ have closely $4.5 \mathrm{keV}$ energy $\mathrm{X}$-rays (4.509 and $4.647 \mathrm{keV}$ ) and also Ti-Ba have same X-ray energies (4.469 and $4.509 \mathrm{keV}$ ). So PIXE not given proper values in case of major elements due to above overlapping peaks.

Since Fe is the major component, the X-ray emitted from this element dominated the energy spectrum in Charnockite matrix composition. Due to above overlapped of the elements in Fe matrix or Charnockite, matrix effects were occurring, and these matrix effects easily understand by using overlapping of spectrums from figures for its evaluation. Some corrections are needed to calculate the exact concentration value of $\mathrm{Fe}$ in Charnockites by PIXE as shown in spectrum 1-7.

Also, between the K X-ray lines of media elements and L X-ray lines of heavy elements causes the inability of proper detection in concentrations. $\mathrm{K}$ and $\mathrm{Ca}$ summing peaks could interfere with $\mathrm{X}$-ray lines of $\mathrm{Fe}, \mathrm{Ni}$ and $\mathrm{Cu}$ in Charnockite composition from the above spectrums study. The other reason [2] also $\mathrm{K}$ and $\mathrm{Ca}$ escape peaks off in this investigation in $\mathrm{Si}(\mathrm{Li})$ detector interfere with $\mathrm{X}$-ray lines of $\mathrm{Al}, \mathrm{Si}, \mathrm{Na}$ and $\mathrm{Mg}$ elements contain in composition.

The tail of the $\mathrm{Zr} \mathrm{k \alpha}$ line obscures the $\mathrm{Y} \mathrm{K \alpha}$ line machine; this effect arises from competition scattering (into the detection) of the $\mathrm{ZrX}$-ray range. The fitting of this type of overlap requires deconvolution of the spectrum of the pure zirconium to determine the correct line shape for the $\mathrm{Zr} \mathrm{K} \alpha \mathrm{X}$-ray. The net result of this problem is that the determine limit for $\mathrm{Y}$ in the $\mathrm{Zr}$ in this energy region of the spectrum, this problem will occur when $\mathrm{X}$-ray generated by trace element occurrence in the presence of X-ray of slightly lighter energy generated by major elements examples including trace $\mathrm{Rb}$ and $\mathrm{Sr}$.

It is then difficult sometimes to deconvolve two peaks from neighbor elements [10]. Also between the $\mathrm{K}$ $\mathrm{X}$-ray lines of media elements and L X-ray lines of heavy elements in the spectrum. To calculate the exact value of concentrations, instead of $2 \mathrm{~mm}$ beam below $1 \mathrm{~mm}$ or micrometer size in the experimental set up and others must be arranged. Therefore the better resolution may be achieved in the analysis of high-grade metamorphic rocks. Although the efficiency of the $\mathrm{Si}(\mathrm{Li})$ detector is low due to the small solid angle, its advantages become very pronounced in the situation of overlapping of the adjacent characteristic lines. The resolution of the standard PIXE arrangement can be drastically improved using the wavelength dispersive spectrometer (WDS) for better resolution [28]. Micro PIXE is an alternative experimental setup in which the diameter of proton beams drastically decreased then the resolution [28] of matrix elements can be minimized.

Because protons are less penetrating than X-rays [3] the PIXE technique samples a less depth in a thick sample. However, the greater sampling depth requires more extensive corrections for interelement and matrix effects. One of the major problems facing in this PIXE analysis of Charnockite thick samples is the extremely small analytical volume. The low bremsstrahlung in PIXE enables parts per million sensitivities, superior to its sister techniques in geological materials are proved. The results obtained indicate that it is competitive with other more classical analytical methods. It may be, in addition, a very useful complementary technique when combined with other ion beam methods like PIGE, EPMA, XRF and NAA.

However, in this work, more sources of overestimation are found then of underestimation. The first group contains the uncertainties in the stopping power, the X-ray attenuation coefficient, the production cross section, the initial proton energy, the angles, the solid angle, and the detector efficiency; it also contains the uncertainties in the number of bombarding particles, and in the X-ray yield. The second group contains the matrix composition in present thick targets and the statistical parts of the uncertainties in the number of bombarding particles, and the X-ray Yield. The main uncertainties are caused by the $\mathrm{X}$-ray yield, the matrix composition, the X-ray attenuation coefficient, the absorber transmission and by the detector efficiency [29].

\section{Conclusions}

The results presented in this study, performance evaluation of PIXE technique in geochemical application through Charnockite analysis is the following conclusions.

In this investigation due to its longer probe depth the PIXE can be performed for a large range of elements $(\mathrm{Cl}<\mathrm{Z}<\mathrm{Pb})$ in the high-grade Charnockite composition. The presented PIXE technique proved its sensitivity, accuracy, precision simplicity and fast of thick target preparation and to perform multi elemental analysis of many complex geological materials.

A possible disadvantage of PIXE at $3 \mathrm{MeV}$ to running in this configuration is that low energy X-rays below or near the sodium are not detected. Because they are absorbed in either the detector window atmosphere or through any filter used. By increasing efficiency of the detector or placing more suitable detectors of by changing the incident proton beam energy or other techniques like PIGE or AAS used in this investigation, these low atomic number $(Z)$ elements can be determined. 
Determination of REE in Charnockite samples is a very important subject, but hard to tackle. By PIXE the L $\mathrm{X}$-rays energies from $4-9 \mathrm{keV}$ strongly overlap with $\mathrm{KX}$-rays energies of light elements (20 to $30 \mathrm{Z}$ ) and the quantification of REE by PIXE with $3 \mathrm{MeV}$ becomes very difficult. For better resolution of low Z elements L X-rays and high Z elements $\mathrm{K} \mathrm{X}$-rays of REE in Charnockites micro PIXE is an alternative experimental setup in which the diameter of proton beams drastically decreased or high energy PIXE is alternative solution for REE. Rare earth elements (REE) have very high thermal neutron cross sections and NAA is usually the first choice for the determination of REEs in a trace elements analysis.

PIXE has certain superiority; moreover the bremsstrahlung produced in PIXE is a secondary effect where as in case of Electron Microprobes and XRF it is primary contributor. The principal source of proton back ground against which the character X-rays of elemental constituents must be distinguished and hence is also the principal determinant of detection limits.

PIXE analysis of the elements present in Charnockites with $Z \leq 30$ an interference is encountered between the $K \alpha$ $(Z+1) X$-ray and the $\mathrm{K} \beta(Z) X$-ray, which have virtually the same energy or between the $\mathrm{X}$-ray $\mathrm{K}$ lines of media elements and X-ray L lines of heavy elements. The elements $\mathrm{K}$ and $\mathrm{Ca}$ summing peaks in matrix composition interfered with X-ray lines of $\mathrm{Fe}, \mathrm{Ni}$ and $\mathrm{Cu}$ have shown in spectrums obtained and also $\mathrm{K}$ and $\mathrm{Ca}$ escape peaks off in this investigation in $\mathrm{Si}(\mathrm{Li})$ detector interfere with X-ray lines of $\mathrm{Al}, \mathrm{Si}, \mathrm{Na}$ and $\mathrm{Mg}$ elements contain in composition. The Fe is the major component so that the X-ray emitted from this element will dominate the energy spectrum of all Charnockite samples. Hence the analyses from PIXE not coincide with the results of AAS. The resolution of the standard PIXE arrangement can be drastically improved using the wavelength dispersive spectrometer (WDS) for better resolution. Micro PIXE is an alternative experimental setup in which the diameter of proton beams drastically decreased then the resolution of matrix elements can be minimized.

However, the characteristic X-ray cross section decreases rapidly as the proton energy decreases, particularly at energies less than $3 \mathrm{MeV}$ for the detection of low $\mathrm{Z}$ elements in element detection. The energy loss at the target cannot be neglected in comparison with incident energy. Therefore, at low energy of proton $(<3 \mathrm{MeV})$ a very thin target for low $\mathrm{Z}$ elements in Charnockite is required for accurate quantitative analysis.

The presented PIXE is known for its sensitivity, accuracy, precision, simplicity and fast of thick target preparation and to perform multi elemental analysis of geological materials like high grade rocks compared with the previous techniques, but the limitation is that low $\mathrm{Z}$ elements, matrix effects and REE. The main uncertainties in PIXE are caused by the
$\mathrm{X}$-ray yield, the matrix composition, the X-ray attenuation coefficient, the absorber transmission and by the detector efficiency. An analysis is made to understand the results behind the poor performance of PIXE with respect to certain elements in this study. The possible reasons behind this have been brought out and evaluated.

The general observation of PIXE methodology indicates that PIXE has been operated at one $3 \mathrm{MeV}$ proton energy with such condition the determination of different elements from low $\mathrm{Z}$ to high $\mathrm{Z}$ is not possible and perhaps this is the most important reasons behind the poor performance of PIXE with respect to the certain elements.

It is suggested to up with an investigation of PIXE by analyzing pure samples of problematic elements; this means $100 \%$ pure elemental powders needed to be analyzed with different concentrations at different levels using a noninterfering matrix so that the optimum conditions for that element can be obtained.

For the further work is needed to understand the problems pertaining to combinations of elements. Such experiments are needed to design to determine different elements in a sample in combination to an optimum condition of analysis. In this way the conditions of PIXE can be standardized for low $\mathrm{Z}$ to high $\mathrm{Z}$ elements under different combinations.

This kind of experimental research is highly necessary to fine tune the performance of PIXE especially when dealing with materials of complexity like high grade metamorphic such as Charnockite.

The present study could establish this aspect for the first time, which will help in future for effective analysis of complex samples using PIXE. This experiment should contribute the conditions of PIXE operation for materials of different complexity and matrix.

In this above PIXE method has been evaluated based on the data pertaining to various elements determined. The evaluated have been made compressing the accessories of elemental concentration in the respective Charnockites. For this purpose, the data have been compared with the standard used mainly USGS. Similarly, the data are compared with the elemental concentrations obtained from the samples studied using another standard technique AAS. The varieties are in accessories intended in various elements having been attempted to explain using the analytical conditions of PIXE. For this purpose, the accessories discussed, and the analysis is presented.

\section{Acknowledgement}

I deem it a privilege to express my deep sense of gratitude and heartiest thanks to Prof. Y. Rama Krishna, Head of the Department, Engineering Physics, Andhra University, 
and Visakhapatnam and for his support and help in the geochemical analysis of the experimental data for his unstinted support and help in the geochemical analysis of the experimental data. I am thankful to Prof. A. Durga Prasad Rao, Head of the Department, Department of Nuclear Physics, Andhra University, Visakhapatnam and teaching staff. I thank Dr. D. P. Mahapatro, Director, Institute of Physics, and Bhubaneswar, providing accelerator facility to carry out the research work and for all amenities provided during our stay at the institute of physics.

\section{References}

[1] M. Ahmed, Journal of Radioanalytical and Nuclear Chemistry 265, 39 (2004).

http://dx.doi.org/10.1007/s10967-005-0786-6.

[2] P. Ana et al., Romanian Reports in Physics. 63, 997 (2011). https://www.academia.edu/18311900/PIXE_ analysis_of_some_vegetal_species

[3] M. F. Araujo, L. C. Alves and J. M. P. Cabral, Nuclear Instruments and Methods in Physics Re $\neg$ search Section B: Beam Interactions with Materials and Atoms 75, 450 (1993). https://doi.org/10.1016/0168583X(93)95694-Z.

[4] W. B. Barnett, Spectrochimica Acta. Part B, Atomic Spectroscopy 39, 829 (1984). https://doi.org/10.1016/0584-8547(84)80091-9.

[5] A. Bello, International Journal of Science and Technology 2, 492 (2012).

https://pdfs.semanticscholar.org/6f04/672ac6866b64 8ab2d78dc636b329219cf8bc.pdf.

[6] N. M. Halden, J. L. Campbell and W. J. Teesdale, The Canadian Mineralogist 33, 293 (1995).

[7] P. C. Chaves, A. Taborda, D. P. S. de Oliveira and M. A. Reis, Nuclear Instruments and Methods in Physics Research Section B: Beam Interactions with Materials and Atoms 318, 37 (2014). https://doi.org/10.1016/j.nimb.2013.05.098.

[8] C. H. Heirwegh, J. L. Campbell and G. K. Czamanske, Nuclear Instruments and Methods in Physics Research Section B: Beam Interactions with Materials and Atoms 366, 40 (2016). https://doi.org/10.1016/j.nimb.2015.10.018.

[9] D. D. Cohen, R. Siegele, I. Orlic and Ed Stelcer, Nuclear Instruments and Methods in Physics Research Section B: Beam Interactions with Materials and Atoms 189, 81 (2002). https://doi.org/10.1016/S0168-583X(01)01011-4.

[10] J. J. G Durocher, N. M. Halden, F. C. Hawthorne and J. S. C. McKee, Nuclear Instruments and Methods in
Physics Research Section B: Beam Interactions with Materials and Atoms 30, 470 (1988). https://doi.org/10.1016/0168-583X(88)90043-2.

[11] A. Ene, I. V. Popescu, T. Badica and C. Besliu, Romanian Reports in Physics 51, 595 (2005).

[12] F. S. Olise et al., Journal of Radiation and Nuclear Applications 2, 95 (2017). http://dx.doi.org/10.18576/jrna/020303.

[13] G. K. Czamanske, T. W. Sisson, J. L. Campbell and W. J. Teesdale, American Mineralogist 78, 893 (1993).

[14] G. Calzolai et al., Nuclear Instruments and Methods in Physics Research Section B: Beam Interactions with Materials and Atoms 266, 2401 (2008). https://doi.org/10.1016/j.nimb.2008.03.056.

[15] G. C. Wilson et al., Nuclear instruments and methods in physics research B; Beam Interactions with Materials and Atoms 189, 387 (2002). http://dx.doi.org/10.1016/S0168-583X(01)01095-3

[16] M. Hajivaliei et al., Nuclear Instruments and Methods in Physics Research Section B: Beam Interactions with Materials and Atoms 160, 203 (2000). https://doi.org/10.1016/S0168- 583X(99)00587-X

[17] H. Kucha, W. Przybylowicz, J. Kajfosz and S. Szymczyk, Geological Quarterly 38, 687 (1994).

[18] K. Ishii and S. Morita, Nuclear Instruments and Methods in Physics Research Section B: Beam Interactions with Materials and Atoms 34, 209 (1988). https://doi.org/10.1016/0168-583X(88)90745-8.

[19] K. Ishii, X-ray Spectrometry 34, 363 (2005). http://dx.doi.org/10.1002/xrs.838.

[20] J. Miranda, Nuclear Instruments and Methods in Physics Research B: Beam Interactions with Materials and Atoms 118, 346 (1996). https://doi.org/10.1016/0168-583X(95)01176-5

[21] S. A. E. Johansson and T. B. Johansson, Nuclear Instruments and Methods in Physics Research B: Beam Interactions with Materials and Atoms 137, 473 (1976). https://doi.org/10.1016/0029-554X(76)90470-5.

[22] M. H. Kabir, Ph.D. Dissertation, Kochi University of Technology Japan (2007).

[23] D. C. Kamineni, M. Bandari and A. T. Rao, American Mineralogist 67, 1001 (1982).

[24] I. Borbely-Kiss et al., Nuclear Instruments and Methods in Physics Research Section B: Beam Interactions with Materials and Atoms 12, 496 (1985). https://doi.org/10.1016/0168-583X(85)90506-3.

[25] J. D. Macarthur and Xin-Pei Ma, International Journal of PIXE 1, 311 (1991). https://doi.org/10.1142/S0129083591000226. 
[26] K. G. Malmqvist et al., Nuclear Instruments and Methods in Physics Research B: Beam Interactions with Materials and Atoms 22, 386 (1987). https://doi.org/10.1016/0168-583X(87)90364-8.

[27] J. A. Maxwell, W. J. Teesdale and J. L. Campbell, Nuclear Instruments and Methods in Physics Research B: Beam Interactions with Ma 7 terials and Atoms 95, 407 (1995). https://doi.org/10.1016/0168-583X(94)00540-0

[28] M. G. Budnar, Nuclear Instruments and Methods in Physics Research B: Beam Interactions with Materials and Atoms 144, 109 (1996). https://doi.org/10.1016/0168-583X(95)00896-9.

[29] F. Munnik, Phd Thesis, Eindhoven University of Technology (1994).

[30] K. Murozono et al., Nuclear Instruments and Methods in Physics Research Section B: Beam Interactions with Materials and Atoms 150, 76 (1999). https://doi.org/10.1016/S0168-583X(98)00918-5

[31] N. M. Halden, J. L. Campbell and W. J. Teesdale, The Canadian Mineralogist 33, 293 (1995).

[32] S. O. Olabanji et al., Nuclear Instruments and Methods in Physics Research Section B: Beam Interactions with Materials and Atoms 262, 109 (1996). https://doi.org/10.1016/0168-583X(95)00919-1.

[33] J. O. Oti Wilberforce, IOSR Journal of Applied Chemistry 9, 15 (2016).

[34] R. Kar, Journal of Earth System Science 110, 337 (2001). https://doi.org/10.1007/BF02702899

[35] A. T. Rao and V. R. R. M. Babu, American Mineralogist 63, 330 (1978).
[36] J. D. Robertson, H. Neff and B. Higgins, Nuclear Instruments and Methods in Physics Research Section B: Beam Interactions with Materials and Atoms 189, 378 (2002). https://doi.org/10.1016/ S0168-583X(01)01093-X.

[37] C. G. Ryan, Nuclear Instruments and Methods in Physics Research Section B: Beam Interactions with Materials and Atoms 219, 534 (2004). https://doi.org/10.1016/j.nimb.2004.01.117

[38] A. V. S. Satyanarayana, S. R. Kumar and S. V. R. A. N. Sharma, Journal of Nuclear Physics, Material Sciences, Radiation and Applications 3, 147 (2016). https://doi.org/10.15415/ jnp.2016.32016.

[39] P. Saradhi, M. Arima, A. T. Rao and M. Yoshida, Journal of Geosciences 43, 177 (2000).

[40] A. Sriramadas and A. T. Rao, Journal Geological Society of India 20, 512 (1979).

[41] B. Abdullahi, M. T. Tsepav, M. D. Oladipupo and B. Alfa, Modern Applied Science 6, 96 (2012). https://doi.org/10.5539/mas.V6n7p96

[42] J. R. Tesmer and M. Nastasi (eds), Modern Ion Beam Material Analysis, Material Research Society. Pittsburgh, Pennsylvania, USA (1995).

[43] G. Calzolai et al., Nuclear Instruments and Methods in Physics Research Section B: Beam Interactions with Materials and Atoms 266, 2401 (2008). https://doi.org/10.1016/j.nimb.2008.03.056.

[44] D. Zhongning et al., Nuclear Instruments and Methods in Physics Research Section B: Beam Interactions with Materials and Atoms 104, 489 (1995). https://doi.org/10.1016/0168-583X(95)00473-4 


\section{Journal of Nuclear Physics, Material Sciences, Radiation and Applications}

Chitkara University, Saraswati Kendra, SCO 160-161, Sector 9-C, Chandigarh, 160009, India

Volume 7, Issue 1

August 2019

ISSN 2321-8649

Copyright: [C 2019 A.V. S. Satyanarayana et al.] This is an Open Access article published in Journal of Nuclear Physics, Material Sciences, Radiation and Applications (J. Nucl. Phy. Mat. Sci. Rad. A.) by Chitkara University Publications. It is published with a Creative Commons Attribution- CC-BY 4.0 International License. This license permits unrestricted use, distribution, and reproduction in any medium, provided the original author and source are credited. 